\title{
Notch signaling inhibits growth of the human lung adenocarcinoma cell line A549
}

\author{
QIJUN ZHENG ${ }^{1,2^{*}}$, HONGYAN QIN ${ }^{1 *}$, HONGWEI ZHANG ${ }^{1 *}$, JUNCHANG LI $^{1}$, \\ LIHONG HOU ${ }^{1}$, HONGBIN WANG ${ }^{2}$, XUEPING ZHANG ${ }^{1}$, SUZHEN ZHANG ${ }^{1}$, \\ LEI FENG ${ }^{1}$, YINGMIN LIANG ${ }^{1}$, HUA HAN ${ }^{1}$ and DINGHUA YI ${ }^{2}$
}

\author{
${ }^{1}$ State Key Laboratory of Cancer Biology, Department of Medical Genetics and Developmental Biology, ${ }^{2}$ Department \\ of Cardiovascular Surgery, Xijing Hospital, Fourth Military Medical University, Xian 710032, P.R. China
}

Received October 26, 2006; Accepted December 22, 2006

\begin{abstract}
In lung cancers the Notch signaling may function as an oncogene or a tumor suppressor depending on the tumor cell types. In this study we examined the expression of Notch receptors in the human lung adenocarcinoma cell lines A549 and SPC-A-1. We over-expressed the active form of Notch1 (NIC) in A549 cells by constitutive transfection to evaluate the effects of the Notch signaling on lung adenocarcinoma cells. Our results showed that over-expression of NIC in A549 cells inhibited the growth of A549 cells through induction of cell cycle arrest. Moreover, over-expression of NIC inhibited the colony-forming activity of A549 cells when cultured in methylcellulose medium, and their ability to form tumors in nude mice. These data suggest that the Notch signaling may function as a tumor inhibitor in human lung adenocarcinoma cells.
\end{abstract}

\section{Introduction}

The Notch signaling pathway plays a pivotal role in cell fate determination during development, and is highly conserved during evolution from worm through man (1). Notch is a hetero-dimeric transmembrane receptor composed of an extracellular domain responsible for ligand recognition, a trans-

Correspondence to: Dr Hua Han, Department of Medical Genetics and Developmental Biology, Fourth Military Medical University, Chang-Le Xi Street 17, Xian 710032, P.R. China

E-mail: huahan@fmmu.edu.cn

Dr Dinghua Yi, Department of Cardiovascular Surgery, Xijing Hospital, Fourth Military Medical University, Xian 710032, P.R. China

E-mail: Yidh@fmmu.edu.cn

${ }^{*}$ Contributed equally

Key words: Notch, human lung adenocarcinoma cells, tumor, cell cycle membrane domain, and an intra-cellular domain involved in protein-protein interaction and transcriptional regulation. When the Notch receptor is triggered by the ligand, the DSL (Delta-Serrate-Lag2) family members expressed on neighboring cells, two successive proteolytic cleavages take place in the transmembrane domain of the receptor, which leads to the release of the Notch intra-cellular domain (NIC). The released NIC translocates into the nucleus and associates with the transcription factor RBP-J through its N-terminal RAM (RBP-J association molecule) motif, and converts RBP-J from a transcription repressor to a transcription activator. The NIC-RBP-J complex further recruits other co-activators, and activates the expression of downstream genes associated with cell differentiation (2). Thus, constitutive expression of NIC in targeted cells results in a similar phenotype as the 'activated' Notch. In addition to the ligands, receptors, and intra-nuclear adaptor, a large array of molecules has been shown to participate in the modulation of the Notch signaling in different developmental stages and tissues $(1,2)$.

Abnormal Notch signaling has been documented in many cancers (3-6). The first case showing the Notch involvement in human malignancies is the identification of a rare chromosomal translocation event, $\mathrm{t}(7 ; 9)(\mathrm{q} 34 ; \mathrm{q} 34.3)$, as a causative factor in the development of T-cell acute lymphoblastic leukemia and lymphoma (T-ALL) (7). This translocation juxtaposes the intra-cellular domain of Notch1 adjacent to the T-cell receptor $\beta$ locus, resulting in the expression of NIC of the Notch1 protein that is hence named as translocationassociated Notch1 (TAN1). In addition to T-ALL, oncogenic activity of Notch has been reported in many other types of cancers, including acute myeloid leukemia (AML) (8), breast cancers (9), as well as human cancers of the cervix, colon, pancreas, skin and brain (reviewed in refs. 4,5). On the other hand, activated Notch signaling may also function as a tumor suppressor $(10,11)$. In prostate cancer cells, over-expression of the active form of Notch1 inhibited the proliferation of tumor cells (12). Constitutive activation of Notch1 also inhibited the growth of human hepatocarcinoma cells through induction of cell cycle arrest and apoptosis (13). Furthermore, in Notchdeficient mice, Notch1 had been shown to function as a tumor suppressor in mouse skin through inhibition of the B-catenin signaling (14). The molecular mechanisms underlying the 
oncogenic and anti-oncogenic activities of Notch have not been fully understood, and are under extensive investigation.

The relationship between the Notch signaling and lung cancers has been elusive $(15,16)$. Evidence has shown that in lung cancers Notch may behave as either an oncogene or a tumor suppressor depending on the tumor cell types. In small cell lung cancer (SCLC) cells, Notch receptors are rarely expressed, and over-expression of NIC leads to a profound growth arrest associated with $\mathrm{G}_{1}$ cell cycle block in the SCLC cell lines DMS53 and NCI-H209 (17). In contrast, in nonsmall cell lung cancers (NSCLC) including adenocarcinoma, squamous cell carcinoma, large cell undifferientiated carcinoma and bronchoalveolar cell carcinoma, expression of the Notch receptors are common and the expression of the Notch downstream gene Hes 1 is usually elevated with a concomitant decrease of hASH1/ASCL1, suggesting an activated Notch signaling in these cells (18-21). However, functional consequences of Notch activation in lung cancer remain unclear.

In order to further investigate the function of the Notch signaling pathway in different types of lung cancers, we studied the Notch signaling in the lung adenocarcinoma cell lines A549 and SPC-A-1. We show that Notch1-3 but not Notch4 are expressed in these cell lines. Over-expression of NIC significantly inhibited the growth of A549 cells in vitro by induction of cell cycle arrest, and attenuated its colonyforming activity in vitro as well as tumor-forming activity in vivo. These results suggest that Notch signaling may inhibit growth and tumor formation ability of human lung adenocarcinoma cells.

\section{Materials and methods}

Cell culture and transfection. The human lung adenocarcinoma cell lines A549 and SPC-A-1 were cultured in Dulbecco's modified Eagle's medium (DMEM) supplemented with $10 \%$ fetal calf serum (FCS) and $2 \mathrm{mM} \mathrm{L-glutamine} \mathrm{(Gibco/BRL).}$ pEFBOS-Myc-NIC and pEFBOS-neo vectors (22) were transfected into A549 cells using Lipofectamine ${ }^{\mathrm{TM}} 2000$ (Invitrogen Life Technologies, Carlsbad, CA) according to the manufacturer's protocol. Stable cell lines (A549-NIC and A549-BOS) were selected in the presence of $450 \mu \mathrm{g} / \mathrm{ml}$ of G-418, and were maintained in DMEM containing $10 \%$ FCS and $300 \mu \mathrm{g} / \mathrm{ml}$ of $\mathrm{G}-418$.

MTT assay. Cells were seeded in $96-$ well plates $\left(4 \times 10^{3}\right.$ cells per well) and cultured in $200 \mu \mathrm{l}$ of the medium. On days 1-6 of the culture, half amount of the medium $(100 \mu 1)$ was aspired and an equal volume of fresh medium containing 20\% MTT $(5 \mathrm{mg} / \mathrm{ml})$ was added. Cells were incubated further at $37^{\circ} \mathrm{C}$ for $4 \mathrm{~h}$, and then $150 \mu \mathrm{l}$ of dimethyl sulfoxide (DMSO, Sigma) was added to each well, and mixed by shaking at room temperature for $10 \mathrm{~min}$. The absorbance was measured at $490 \mathrm{~nm}$. Each experiment was repeated for at least three times, and data were analyzed with the Student's t-test.

Cell cycle analysis. Cells $\left(1 \times 10^{6}\right)$ were collected and washed with PBS, then fixed by incubating in $75 \%$ alcohol for $30 \mathrm{~min}$ at $4^{\circ} \mathrm{C}$. After washing with cold PBS three times, cells were resuspended in $1 \mathrm{ml}$ of PBS containing $40 \mu \mathrm{g}$ propidium iodide (PI, Sigma) and $100 \mu \mathrm{g}$ RNase A (Sigma), and incubated at $37^{\circ} \mathrm{C}$ for $30 \mathrm{~min}$. Samples were analyzed for DNA contents using a FACScalibur ${ }^{\mathrm{TM}}$ (BD Immunocytometry Systems, San Jose, CA). Each experiment was repeated for at least three times.

Colony-forming assay. Cells $\left(5 \times 10^{4} / \mathrm{ml}\right)$ were mixed with $1 \mathrm{ml}$ MethoCult methylcellulose-based medium (StemCell Technologies, Vancouver, British Columbia, Canada), and were plated in 6-well plates according to the manufacturer's instructions. Cells were cultured at $37^{\circ} \mathrm{C}$ for 7 days, and colonies (with $>50$ cells) were counted under an inverted microscope.

In vivo inoculation of tumor cells. Cells $\left(5 \times 10^{6}\right)$ were injected subcutaneously (s.c.) into female nude mice $(n=6)$. Six weeks later, mice were sacrificed and tumor formation was examined. Mice were housed in a pathogen-free facility, and all animal experiments were carried out according to guidelines of the Animal Experiment Administration Committee of the Fourth Military Medical University.

Reverse transcription (RT)-polymerase chain reaction (PCR). Total-RNA was prepared from cultured cells using the TRIzol reagent (Gibco/BRL, Gaithersberg, MD) according to the manufacturer's instructions. cDNA was synthesized using a kit from Gibco/BRL with oligo-dT as a primer. PCR was run for 25 cycles with cDNA from $0.1 \mu \mathrm{g}$ total-RNA as a template. The primers used for the amplification of human Notch1-4 cDNA and glyceraldehyde-3-phosphate dehydrogenase (GAPDH) fragments are listed in Table I. The amplified fragments were analyzed by electrophoresis with $1 \%$ agarose gel.

Western blot analysis. Cells were lysed in the phospho-lysis buffer (50 mM Tris-Cl, pH 7.5, $150 \mathrm{mM} \mathrm{NaCl}, 1 \mathrm{mM} \mathrm{MgCl}$, $0.5 \% \mathrm{NP} 40,1 \mathrm{mg} / \mathrm{ml} \mathrm{BSA}, 0.1 \mathrm{mM}$ PMSF). Cell extracts were collected by centrifugation. Samples were analyzed by SDS-12\% polyacrylamide gel electrophoresis, followed by Western blotting using the mouse anti-Myc antibody (Sigma) and the goat anti-mouse IgG antibody conjugated with horseradish peroxidase (HRP). The membrane was developed using the chemiluminescent reagents (SuperSignal West Femto Maximum Sensitivity Substrate, Pierce).

\section{Results}

The human lung adenocarcinoma cell lines express Notch1-3 but not Notch4. To test the expression of the Notch receptors in the human lung adenocarcinoma cell lines A549 and SPCA-1, we carried out an RT-PCR analysis with primers specifically targeting the four Notch receptors. As shown in Fig. 1A, Notch1-3, but not Notch4, were expressed in both of the cell lines. Taken GAPDH as an internal control, A549 appeared to express lower level of the Notch receptors compared with SPC-A-1. We examined the in vitro growth of A549 and SPC-A-1 cells, and the result showed that A549 cells grew more rapidly compared with SPC-A-1 cells (Fig. 1B), suggesting that Notch may also play a tumor-inhibiting role in human adenocarcinoma cells.

Over-expression of NIC inhibits growth of the A549 cells in vitro. In order to further investigate whether the Notch 
Table I. Primers for RT-PCR.

\begin{tabular}{llr}
\hline Genes & \multicolumn{1}{c}{ Primers } & Size of targets (bp) \\
\hline Notch1 & Sense: 5'-CAGCCTCACCTGGTGCAGAC-3' & 518 \\
& Antisense: 5'-GGCGATCTGGGACTGCATG-3' & 301 \\
Notch2 & Sense: 5'-AGCTCAGACCATTCTCCCAGC-3' & \\
& Antisense: 5'-GTTGTGTGGTGGCTCAGACATG-3' & 401 \\
Notch3 & Sense: 5'-CTCATCCGAAACCGCTCTACAG-3' & 508 \\
Notch4 & Antisense: 5'-AGCAAGCGCACGATGTCCT-3' & \\
& Sense: 5'-CCAGAGGCCCGTCACAAAG-3' & 327 \\
\hline
\end{tabular}
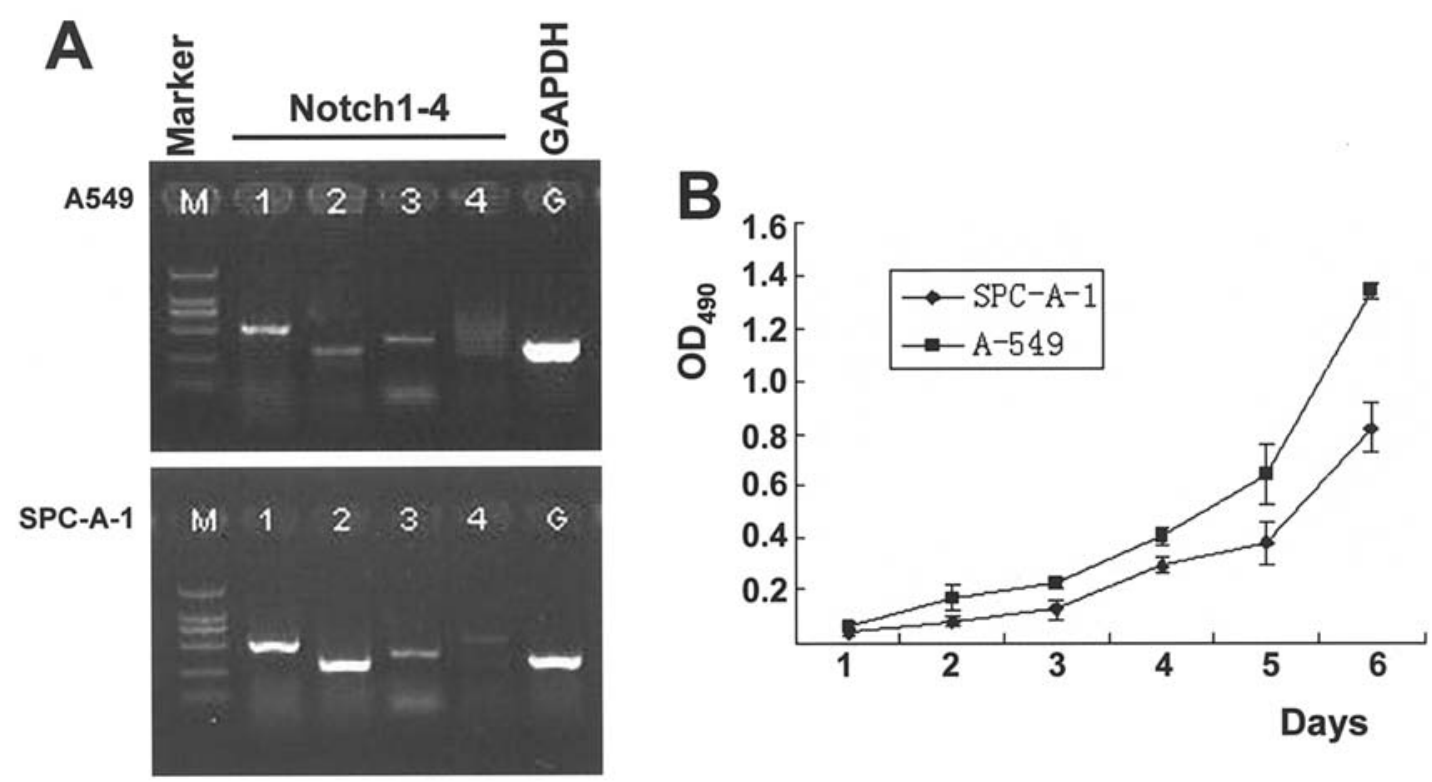

Figure 1. Expression of the Notch receptors in A549 and SPC-A-1 cells. (A) RT-PCR, with GAPDH as an internal control. (B) Growth curves of A549 and SPC-A-1 cells, as determined by the MTT assay.

signaling would function in lung adenocarcinoma cells, we established A549 cells stably transfected with plasmids expressing the Myc-tagged NIC (A549-NIC), with cells transfected with empty vector (A549-BOS) as a control. Expression of Myc-NIC in A549-NIC was confirmed by Western blot using the mouse anti-Myc antibody (Fig. 2A). The growth of the A549-NIC cells was compared with the A549-BOS cells and the parental A549 cells. As shown in Fig. 2B, the growth of the A549-NIC cells was significantly slower than that of the A549-BOS and the parental A549 cells. We analyzed the cell cycle progression of the A549NIC and A549-BOS cells. As shown in Fig. 2C, the A549NIC cells exhibited higher proportion of cells in the $G_{1}$ phase compared with that of the control A549-BOS cells, suggesting that over-expression of NIC inhibited cell cycle progression of the A549 cells.
Over-expression of NIC inhibits tumor growth of A549 in nude mice. We further examined the effect of NIC over-expression on the ability of the A549 cells to form tumors. We first performed an in vitro colony-forming assay to compare the colony-forming ability of A549 cells over-expressing NIC with control cells, and found that the colony-forming ability of A549-NIC was significantly lower than that of A549-BOS and the parental A549 cells $(\mathrm{P}<0.01)$. However, there were not significant difference between A549-BOS and parental A549 cells $(\mathrm{P}>0.05)$ (Fig. 3). These data indicated that overexpression of the constitutively active Notch 1 could substantially inhibit the colony-forming activity of human lung adenocarcinoma cells in vitro.

Next we examined the tumorigenicity of the A549-NIC cells and the A549-BOS cells in nude mice. Four of six mice injected with the A549-NIC cells formed tumors, while all 

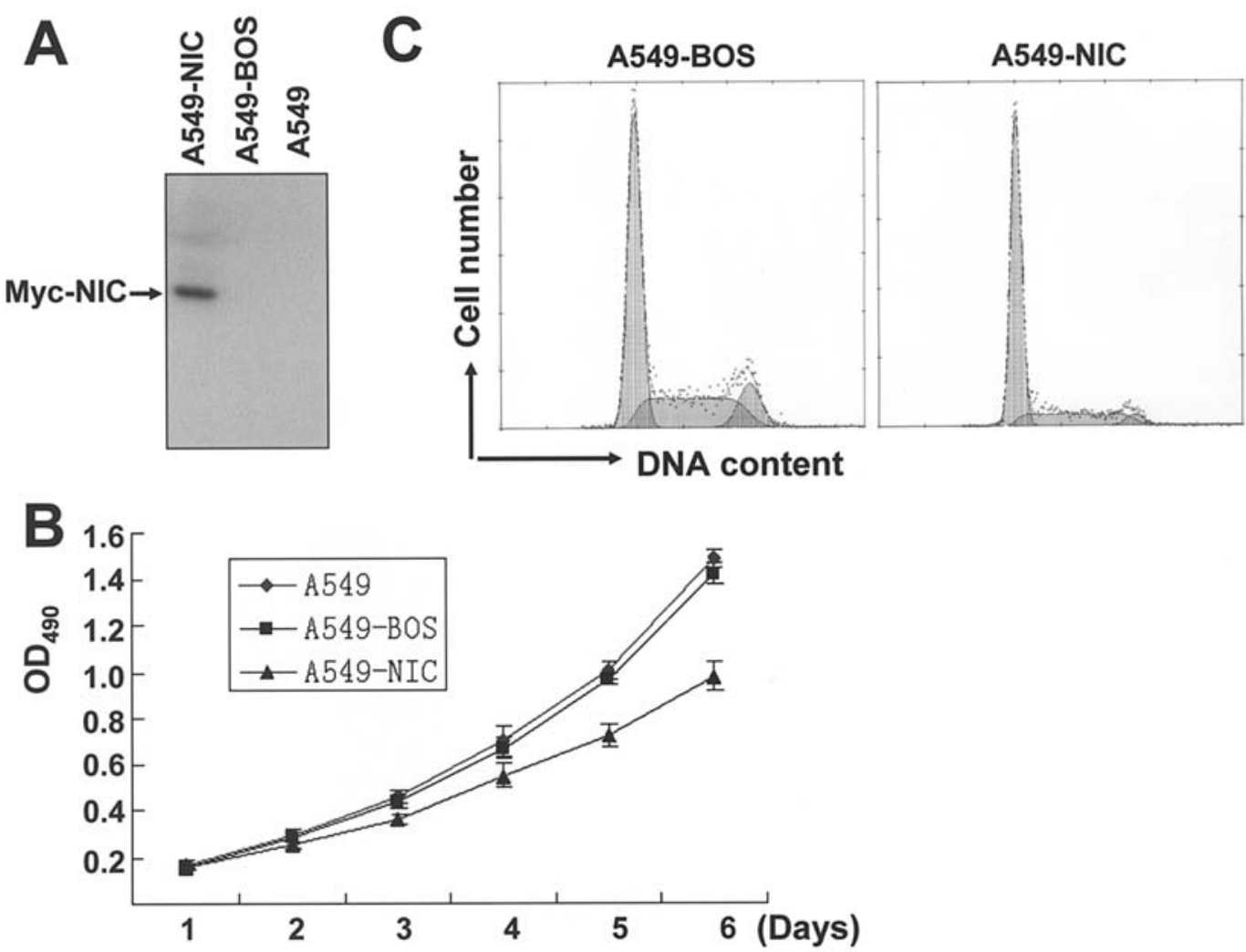

Figure 2. Constitutively active Notch1 inhibits the growth of the lung adenocarcinoma A549 cells in vitro. (A) Expression of Myc-NIC (indicated by an arrow) in the A549-NIC, A549-BOS, as well as parental A549 cells was detected by Western blot with the anti-Myc antibody. (B) Growth of A549-NIC cells was compared with that of the A549-BOS and parental A549 cells. (C) Cell cycle analysis. A549-NIC and A549-BOS cells were permeated and stained with PI, and cell cycle progression was analyzed by FACS. Data represent three independent experiments.

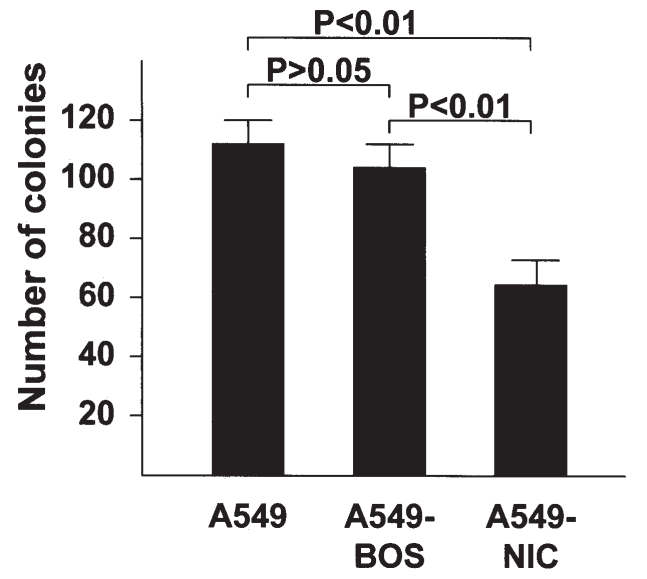

Figure 3. Colony-forming assay. A549-NIC, A549-BOS and parental A549 cells were cultured in MethoCult methycellulose-based medium, and colonies with $>50$ cells were counted 7 days later. The experiment was repeated three times, and data shown are means \pm SD.

six mice injected with the A549-BOS cells formed tumors. The size of tumors in mice injected with the A549-NIC cells were significantly smaller than that in mice injected with the A549-BOS cells (Fig. 4A), and tumor weight in mice injected with the A549-NIC cells were also significantly lower than that in mice injected with the A549-BOS cells $(\mathrm{P}<0.01)$ (Fig. 4B). These results indicated that over-expression of the active Notch1 may suppress the growth of lung adenocacinoma cells in vivo.

\section{Discussion}

During the lung development, the Notch signaling pathway regulates differentiation of a common airway epithelial precursor with a potential for either neuroendocrine or nonneuroendocrine differentiation $(15,16)$. It has been shown that the Notch pathway in lung cancers may also exhibit binary properties. In SCLC, Notch appears to have a growth suppressing function (17). In NSCLC, on the other hand, Notch may have a growth promoting function (18-21). However, in the present study, we have shown an alternative effect of the active form of Notch1 in lined cells (A549) of the human adenocarcinoma, a type of NSCLC. Our results of the in vitro transfection experiments have shown that overexpression of the activated Notch1 in the A549 lung adenocarcinoma cell line induces growth inhibition and cell cycle arrested in the $\mathrm{G}_{1}$ phase. Moreover, over-expression of NIC inhibited the in vitro colony-forming activity and the in vivo tumor-forming ability of the A549 lung adenocarcinoma cells. These results suggest that in NSCLC cells, activated Notch may function as either an oncogenic factor or a tumor suppressor factor, possibly depending on the cell type and the disease-stage of the cancer (10).

It is known that in a number of tumors, such as T-ALL (7) and mouse mammary tumors (9), Notch signaling plays an 

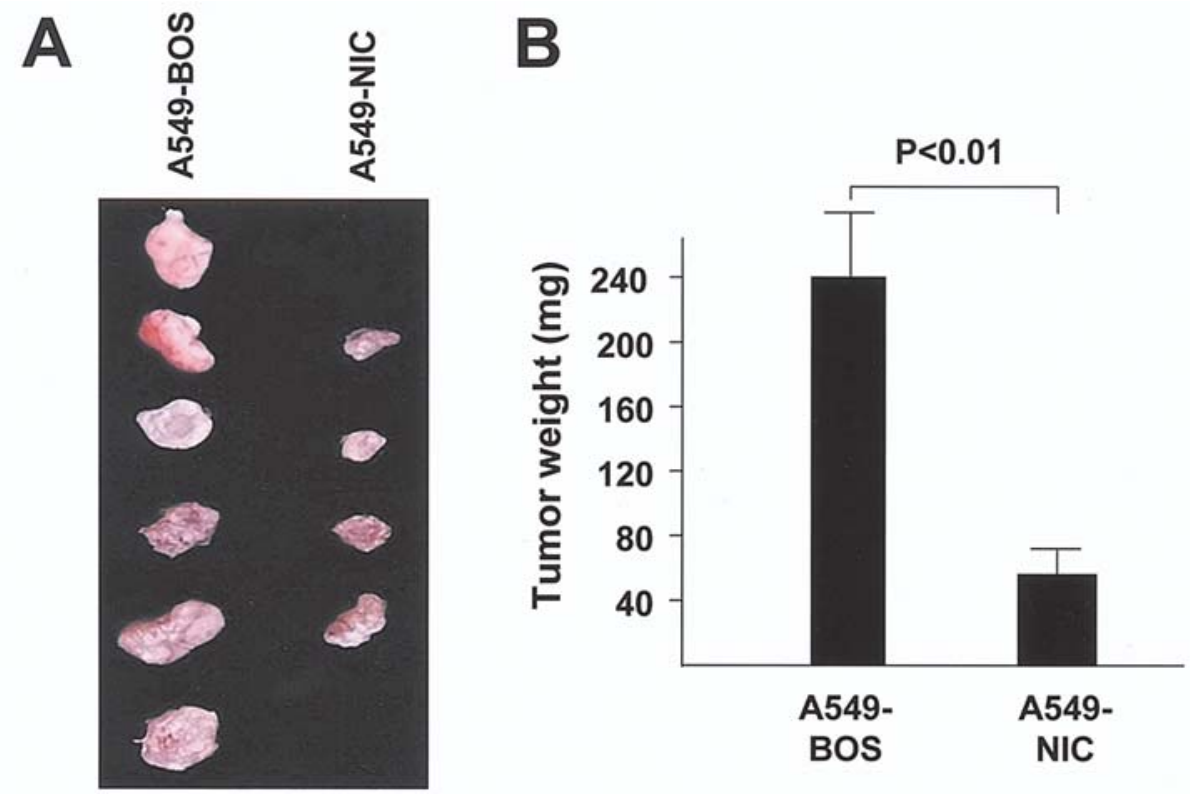

Figure 4. Over-expression of NIC suppresses tumor growth of A549 in nude mice. A549-NIC or A549-BOS cells (5x10 6 ) were injected s.c. into 6 female nude mice separately. Tumors were dissected from the mouse tissues 6 weeks later (A), and tumor weight in each group was measured (B).

oncogenic role by inhibition of apoptosis and induction of proliferation $(4,5)$. However, recent studies have shown that, depending on the cell context, the Notch signaling may also function oppositely in tumorigenesis. For example, constitutive Notch signaling by over-expression of NIC in B-cells has been shown to inhibit proliferation and/or induce apoptosis $(23,24)$. It has also been shown that ligand-induced Notch activation may have a similar effect (25). In human cervical cancers, expression level of Notch1 protein is dependent on disease-stage, and over-expression of activated Notch1 results in strong growth inhibition of HPV-positive cervical carcinoma cells (26). In SCLC, expression of activated Notch 1 or Notch2 up-regulates the expression of $\mathrm{p} 21^{\mathrm{Cip} 1}$ and $\mathrm{p} 27^{\mathrm{Kip} 1}$, leading to cell cycle arrest (17). In this study, we show that in lung adenocarcinoma cells, Notch activation may also play a tumor suppressive role, although previous evidence has highlighted an oncogenic effect of Notch signaling in this type of NSCLC. Additional studies are needed to determine the molecular mechanisms underlying the Notch-induced growth suppression of lung adenocarcinoma cells.

\section{Acknowledgements}

This study was supported by grants from National Natural Science Foundation of P.R. China (30330550 and 30425015). H.H. is supported by the PCSIRT program (IRT0459) of the Ministry of Education of P.R. China.

\section{References}

1. Artavanis-Tsakons S, Rand MD and Lake RJ: Notch signaling: cell fate control and signal integration in development. Science 284: 770-776, 1999.

2. Honjo T: The shortest path from the surface to the nucleus RBP-Jk/Su (H) transcription factor. Genes Cells 1: 1-9, 1996

3. Hansson E, Lendahl U and Chapman G: Notch signaling in development and disease. Semin Cancer Biol 14: 320-328, 2004.
4. Axelson H: Notch signaling and cancer: emerging complexity. Semin Cancer Biol 14: 317-319, 2004.

5. Leong KG and Karsan A: Recent insights into the role of Notch signaling in tumorigenesis. Blood 107: 2223-2233, 2006.

6. Nam Y, Aster JC and Blacklow SC: Notch signaling as a therapeutic target. Curr Opin Chem Biol 6: 501-509, 2002.

7. Screpanti I, Bellavia D, Campese AF, Frati L and Gulino A: Notch, a unifying target in T-cell acute lymphoblastic leukemia? Trends Mol Med 9: 30-35, 2003.

8. Chiaramonte R, Basile A, Tassi E, Calzavara E, Cecchinato V, Rossi V, Biondi A and Comi P: A wide role for notch1 signaling in acute leukemia. Cancer Lett 219: 113-120, 2005.

9. Dievart A, Beaulieu N and Jolicoeur P: Involvement of Notch1 in the development of mouse mammary tumors. Oncogene 18: 5973-5981, 1999.

10. Weng AP and Aster JC: Multiple niches for Notch in cancer: context is everything. Curr Opin Genet Dev 14: 48-54, 2004.

11. Bigas A, Martin DI and Milner LA: Notch1 and Notch2 inhibit myeloid differentiation in response to different cytokines. Mol Cell Biol 18: 2324-2333, 1998.

12. Shou JY, Ross S, Koeppen H, De Sauvage FJ and Gan WQ: Dynamics of Notch expression during murine prostate development and tumorigenesis. Cancer Res 61: 7291-7297, 2001.

13. Qi RZ, An HZ, Yu YZ, Zhang MH, Liu SX, Xu HM, Guo ZH, Cheng T and Cao XT: Notch1 signaling inhibits growth of human hepatocellular carcinoma through induction of cell cycle arrest and apoptosis. Cancer Res 63: 8323-8329, 2003.

14. Nicolas M, Wolfer A, Raj K, Kummer JA, Mill P, van Noort M, Hui CC, Clevers H, Dotto GP and Radtke F: Notch1 functions as a tumor suppressor in mouse skin. Nat Genet 33: 416-421, 2003.

15. Collins BJ, Kleeberger W and Ball DW: Notch in lung development and lung cancer. Semin Cancer Biol 14: 357-364, 2004.

16. Daniel VC, Peacock CD and Watkins DN: Developmental signaling pathways in lung cancer. Respirology 11: 234-240, 2006.

17. Sriuranpong V, Borges MW, Ravi RK, Arnold DR, Nelkin BD, Baylin SB and Ball DW: Notch signaling induces cell cycle arrest in small cell lung cancer cells. Cancer Res 61: 3200-3205, 2001.

18. Ball DW: Achaete-scute homolog-1 and Notch in lung neuroendocrine development and cancer. Cancer Lett 204: 159-169, 2004.

19. Sriuranpong V, Borges MW, Strock CL, Nakakura EK, Watkins DN, Blaumueller CM, Nelkin BD and Ball DW: Notch signaling induces rapid degradation of achaete-scute homolog 1. Mol Cell Biol 22: 3129-3139, 2002. 
20. Chen H, Thiagalingam A, Chopra H, Borges MW, Feder JN, Nelkin BD, Baylin SB and Ball DW: Conservation of the Drosophila lateral inhibition pathway in human lung cancer: a hairy-related protein (HES-1) directly represses achaete-scute homolog-1 expression. Proc Natl Acad Sci USA 94: 5355-5360, 1997.

21. Haruki N, Kawaguchi KS, Eichenberger S, Massion PP, Olson S, Gonzalez A, Carbone DP and Dang TP: Dominant-negative Notch3 receptor inhibits mitogen-activated protein kinase pathway and the growth of human lung cancers. Cancer Res 65 : 3555-3561, 2005.

22. Qin HY, Wang JS, Liang YM, Taniguchi Y, Tanigaki K and Han H: RING1 inhibits transactivation of RBP-J by Notch though interaction with LIM protein KyoT2. Nucleic Acids Res 32: 1492-1501, 2004.
23. Morimura T, Goitsuka R, Zhang Y, Saito I, Reth M and Kitamura D: Cell-cycle arrest and apoptosis induced by Notch1 in B cells. J Biol Chem 275: 36523-36531, 2000.

24. Zweidler-McKay PA, He Y, Xu L, Rodriguez CG, Karnell FG, Carpenter AC, Aster JC, Allman D and Pear WS: Notch signaling is a potent inducer of growth arrest and apoptosis in a wide range of B-cell malignancies. Blood 106: 3898-3906, 2005.

25. Tohda S, Murata-Ohsawa M, Sakano S and Nara N: Notch ligands, Delta-1 and Delta-4 suppress the self-renewal capacity and long-term growth of two myeloblastic leukemia cell lines. Int J Oncol 22: 1073-1079, 2003.

26. Talora C, Sgroi DC, Crum CP and Dotto GP: Specific downmodulation of Notch1 signaling in cervical cancer cells is required for sustained HPV-E6/E7 expression and late steps of malignant transformation. Genes Dev 16: 2252-2263, 2002. 